\title{
Por uma Educação Musical crítica frente ao consumo e à alienação
}

\author{
André Bernardes Pereira ${ }^{1}$ \\ Eliton Perpetuo Rosa Pereira ${ }^{2}$ \\ Cristiano Aparecido da Costa ${ }^{3}$
}

Submetido em: $31 / 12 / 2020$

Aprovado em: 18/03/2021

DOI: $10.5965 / 2358092525252021253$

1. Licenciado em Música pelo IFG. Fagotista da Orquestra de Câmara Goyazes, Orquestra Sinfônica de Ribeirão Preto e da Orquestra Sinfônica de Goiânia. Atua como docente na Seduc-MT.E-mail: elitonpereira@gmail.com.

2. Doutor em Educação (Universidade de Santiago de Compostela - Espanha). Atua no curso de Licenciatura em Música e Mestrado em Artes do IFG.

3. Pós-Doutor e Doutor em Educação - FE-UFG. Atua no curso Técnico em Instrumento Musical, Licenciatura em Música e Mestrado em Artes do IFG. 


\section{RESUMO}

O objetivo geral desta pesquisa é compreender como a teoria crítica contribui para pensarmos uma educação musical mais reflexiva e resistente frente ao consumo e a alienação. Temos por base algumas teorias de resistência à influência da indústria cultural e a busca por uma formação musical em consonância com ideários de uma sociedade mais autônoma. Tendo por fundamentos os estudos de Theodor Adorno, e outros autores ligados à Teoria Crítica, procuramos contemplar a proposta de compreender a relação entre música e consumo. Desse modo, foi realizada uma pesquisa de opinião com docentes e estudantes de música de uma instituição de ensino superior para demonstrar pontos relativos ao consumo e à formação humana nas aulas de música. A análise qualitativa dos dados dessa pesquisa foi embasada nas seguintes categorias: consumo, alienação e resistência à indústria cultural. Destarte, procuramos compreender como os elementos de uma formação crítica podem contribuir para pensarmos uma educação musical mais reflexiva e resistente frente ao consumo e alienação.

Palavras-chave: educação musical, consumo, indústria cultural. 


\section{ABSTRACT}

The general objective of this research is to understand how critical theory contributes to thinking about a more reflective and resistant music education in the face of consumption and alienation. We are based on some theories of resistance to the influence of the cultural industry and the search for a musical formation in line with the ideas of a more autonomous society. Based on the studies of Theodor Adorno, and other authors linked to Critical Theory, we seek to contemplate the proposal to understand the relationship between music and consumption. Thus, an opinion poll was conducted with music teachers and students from a higher education institution to demonstrate points related to human consumption and training in music classes. The qualitative analysis of the data in this research was based on the following categories: consumption, alienation and resistance to the cultural industry. Thus, we seek to understand how the elements of a critical formation can contribute to thinking about a more reflective and resistant musical education in the face of consumption and alienation.

Keywords: music education, consumption, cultural industry. 


\section{INTRODUÇÃO}

Atualmente a música é usada em muitos espaços comerciais: shopping centers, lojas, supermercados, restaurantes e até mesmo em consultórios (HERRINGTON; CAPELLA, 1996). Destarte, se faz necessário compreender a forma como as pessoas reagem a essas músicas, como os comerciantes escoIhem seus repertórios musicais e o que eles esperam em termos de reações dos clientes. Em muitos casos, as músicas têm sido escolhidas de forma consciente; havendo, também, uma intenção específica por trás da escolha de determinado repertório, estilo ou ritmo. Nesse contexto, o comportamento dos clientes é manipulado por músicas que provocam distintas sensações.

Acredita-se que esta realidade se apresenta para os estudiosos da educação, para os educadores musicais, sociólogos e músicos, como um campo aberto para pesquisa e reflexão. Neste sentido, é conhecida a influência da indústria cultural ${ }^{4}$ na prática do consumo (MILLIMANN, 1982). Assim, é fundamental, no contexto da educação musical, haver um trabalho de conscientização em relação aos hábitos envolvidos. Conforme nos explica Zanolla (2013) é importante refletir, com base em Theodor Adorno (1994, 1995), a relação entre arte, música, educação e formação na perspectiva da teoria crítica da sociedade ${ }^{5}$.

O objetivo geral desta pesquisa é compreender como a teoria crítica contribui para pensarmos uma educação musical mais reflexiva frente o consumo e a alienação ${ }^{6}$. Inicialmente verificaremos como a música é utilizada para incentivar e induzir o consumo. Discorremos sobre música e alienação, e propomos com base em Theodor Adorno a conscientização e resistência às imposições da mercantilização, também pensando a formação do educador musical. Procuramos demonstrar nossas constata-

\footnotetext{
4. Para o conceito de Indústria Cultural ver as páginas 92 até 99 do texto de Adorno (1993a).

5. Os autores do artigo também têm publicado vários textos com abordagens semelhantes, os quais buscam refletir sobre uma educação musical crítica e humanista (COSTA, 2016, 2018; PEREIRA, 2016; 2017).

6. Investigação acadêmica realizada no Instituto Federal de Goiás (PEREIRA, 2017).
} 
ções e proposições tendo por base as teorias apresentadas por Adorno (1994, 1995, 2011), Kant (1995) e Zanolla (2002, 2013). Alguns estudiosos do campo do marketing também contribuem para embasar as constatações relacionadas ao contexto do consumo, em Holbrook e Hirschman (1982), Malhotra (2001), Richins (1997), Sheth, Mittal e Newman (2008).

Ainda, desenvolvemos uma pesquisa com alguns docentes e estudantes do curso de Licenciatura em Música7, detalhada mais à frente. A maioria dos sujeitos, mesmo entre os estudantes, já atuam profissionalmente como músicos e professores de música. As questões propostas e respondidas foram analisadas tendo por base as categorias teóricas apresentadas, procurando compreender concepções educativas e perfis de consumo. Por fim, propomos a relação das teorias estudadas com a atuação dos docentes e futuros docentes na atividade formativa musical.

Acreditamos que nossa proposta investigativa oportuniza reflexões sobre formas de resistência ao sistema contemporâneo de consumo e alienação (ADORNO, 1995a). Com destaque para o papel dos educadores musicais nesse processo formativo, de modo que possibilite uma ampliação da consciência dos educandos em relação ao contexto social (COSTA, 2016, 2018; PEREIRA, 2016; 2017).

\section{CONSUMO, MÚSICA E ALIENAÇÃO}

A música vem despertando, nas últimas décadas, diversificados interesses no campo do marketing para sua utilização nas estratégias de indução ao consumo (BASTOS, 2013). Conforme Holbrook e Hirschman (1982), atualmente o consumidor adquire diferentes experiências, que traspassam a procura dos produtos buscando impelir atitudes e julgamentos. Para Malhotra (2001) é necessário destacar toda a experiência vivida pelo consumidor, pois para ele a experiência de compra pode ser constatada quando o consumidor tem qualquer tipo de sensação ou

7. Licenciatura em Música do IFG: Link http://cursos.ifg.edu.br/info/lic/lic-musica/CP-GOIANIA 
memória acionada por meio da interação com diferentes atributos na atmosfera de um estabelecimento comercial. Richins (1997) e Malhotra (2001) chegam a mensurar, através de escalas e modelos, as experiências de consumo na atualidade.

A experiência do consumidor conduz, por meio da percepção, a fatos anteriormente vivenciados e, pelos traços de humor e personalidade, podem aproximá-los ou afastá-los de um ambiente de consumo. Segundo Sheth, Mittal e Newman (2008) esse processo da percepção tem três estágios: sensação, organização e interpretação. Underhill (1999) explica que, ao estimular os cinco sentidos, pode ser criada uma experiência de conforto, aumentando consequentemente o número das vendas.

Segundo Kotler (1973), o termo atmosfera refere-se a um espaço que tem a eficácia de produzir diversos efeitos comportamentais sobre o consumidor. Essa influência causada pelo ambiente de compra permite a modelagem do consumidor ao entorpecer intencionalmente suas percepções (BLACKWELL; MINIARD; ENGEL, 2001). Millimann (1982) fez um estudo em supermercados e constatou que os consumidores reagiam de diferentes formas à música rápida e lenta, sendo que na música lenta os consumidores aumentavam o volume de compras, pois os compradores caminhavam mais devagar e escolhiam mais produtos. Redes de fast-food não utilizam músicas suaves, pois sua especificidade é a velocidade, pois quanto mais rápido o cliente adquirir o produto e sair, mais vantajoso será (MILLIMANN, 1982). Lojas que vendem produtos de preços mais elevados e livrarias tendem a tocar músicas mais lentas, pois segundo Mowen e Minor (2003) os clientes são propensos a escolher os produtos de forma mais seletiva.

Tendo por base essas constatações técnicas e científicas, questionamos se existem teorias ou estudos relevantes no âmbito do conhecimento filosófico, sociológico e educacional acerca desses processos de alienação. Verificamos em Adorno (1983, 1994, 1995a, 1995b, 2011), estudos que embasam as constatações que aqui denunciamos.

Adorno (2011) demonstra as reações dos ouvintes e como são utilizadas as músicas para a formação das predileções e 
hábitos, dominando o inconsciente e adequando o indivíduo. Para ele, nem sempre o ouvinte tem consciência das implicações técnicas e estruturais da música, pois a maioria "compreende a música tal como se compreende, em geral, a própria linguagem, mesmo que se desconheça ou nada saiba sobre sua gramática e sintaxe, ou seja, dominando inconscientemente a lógica musical imanente" (ADORNO, 2011, p. 62).

Deste modo, a educação musical deve buscar, em seus processos formativos, o desenvolvimento da reflexão e da conscientização. Segundo Kant (1995) a educação pode nutrir o progresso da capacidade e coragem no ser humano de sair do seu estado de comodidade, tutoria e submissão - o libertando das amarras sociais e o possibilitar auferir a maioridade, convertendo-o em um sujeito autônomo e ético.

Com base nesta premissa, segundo Adorno (1995a), a produção da consciência verdadeira tem a intenção de proporcionar o desenvolvimento da autonomia, o pensar por si, onde as pessoas se libertam de outros que pensam por elas, saindo da menoridade (KANT, 1995). Essa comodidade, mencionada por Kant, que impede a saída do indivíduo da menoridade, se alinha a estandardização estrutural da música, que segundo Adorno (1994) leva o ouvinte a ouvir apenas o simples, não exigindo esforço e dispensando qualquer processo de concentração ou discernimento.

O conceito da pseudo-individuação é analisado por Adorno (1994), que corrobora o caráter ideológico da música de massa na preservação da realidade material. Neste sentido, o ouvinte perde a faculdade de distinguir e rotular músicas e grupos musicais, mas essa identificação não é considerada no contexto estrutural. Esse reconhecimento de materiais musicais e produtos são feitos pela técnica da rotulação determinada pelas marcas. A livre-escolha de músicas e produtos se fetichiza sob as condições do monopólio cultural transformando-a em mercadoria. Adorno, apropriando-se do conceito marxista de 'fetichismo da mercadoria', aborda o âmbito dessas mercadorias culturais, conceituando-as como "a veneração do que é autofabricado, o qual, por sua vez, na qualidade de valor de 
troca se aliena tanto do produtor como do consumidor, ou seja, do homem" (ADORNO, 1983, p. 172).

A indústria cultural, no contexto do fetichismo, de acordo com Adorno (1994) estabelece padrões e gostos, criando necessidades artificiais de desejo e consumo. Por outro lado, a submissão do consumidor e a pseudo-individuação pode ser revertida, pois, segundo Adorno (1983):

Toda a produção da ciência está condicionada ao cumprimento de juízos de valores, para o bem ou para o mal, quer seus agentes tenham ou não consciência disso. Tal procedimento possibilitaria a tomada de consciência das consequências irracionais dessa racionalidade que, potencialmente, possui a condição do exercício da verdadeira emancipação do reino das necessidades. (ADORNO, 1983, p. 52)

Assim, consideramos que a educação musical pode ser um espaço para ampla formação do sujeito em relação aos modos de consumo na atualidade, ampliando a consciência e possibilitando resistência crítica a relações de opressão social de toda ordem.

\section{PROPOSTA FORMATIVA PARA CONSCIÊNCIA E RESISTÊNCIA}

A ilusão de que o homem tem plena liberdade é questionada em reflexões feitas por Adorno e Kant, assim como as relações sociais e de trabalho, educação, servilismo, emancipação e autonomia. No contexto social total, com foco no papel da educação, Adorno (1995a) demonstra a importância de se evitar a barbárie, o totalitarismo ou qualquer outra forma que subjuga e aliena. Esse processo de alienação, segundo Adorno e Horkheimer (1985) advém da busca da dominação da natureza, que se ampliou para o domínio do homem sobre outro homem, da minoria sobre a maioria. 
Nesse sentido, de acordo com Adorno (1995a), a educação intervém na formação social do indivíduo, legitimando esse processo. A educação tradicional, como é possível inferir dos escritos de Adorno e Horkheimer (1985), calcada no ordenamento e na adequação do meio de produção ${ }^{8}$ e consumo, demonstra a característica do ser humano de se livrar do medo e buscar o domínio da natureza, abandonando temores a fenômenos naturais. Toda gama de completude do ser, a natureza, o mítico e o religioso cedem lugar ao que é quantificado, calculado, previsível e mutável, ou seja, uma educação positivista. De modo que esse 'esclarecimento', pressupõe-se conquistado pela luta contra o medo e pelo domínio do mundo natural, agindo submisso à economia e à técnica (ADORNO; HORKHEIMER, 1985). No entanto, o conhecimento, como instrumento de exploração por um determinado grupo, domina, aliena e cria a falsa liberdade ou a pseudo-individuação.

A proposta de formação e resistência do sujeito por meio da educação (ADORNO, 1995a), objetiva se opor à passividade e impotência social, e faz frente às forças da produtividade técnica e indústria cultural, determinando valores que constituirão elementos para reflexão sobre a sujeição. Essa formação deverá ser uma reconstrução integrada de conhecimentos, que refutará o sentido ideológico congelado da cultura que impõe desejos e necessidades.

O conhecimento técnico, como fonte de poder, domina e subjuga. O esclarecimento, sendo restrito a alguns, pode levar a continuidade dessa dominação, cerceando a autonomia e emancipação coletiva. Se o conhecimento fortalece o poder, sua ausência torna o indivíduo subserviente (ADORNO; HORKHEIMER, 1985). O esclarecimento, ao ser assenhorado pela classe dominante, reduz o sujeito a indivíduo passivo, sem reflexão.

8. "Meios de Produção. Conjunto formado pelos meios de trabalho e pelo objeto de trabalho. Os meios de trabalho incluem os instrumentos de produção (ferramentas, máquinas), as instalações (edifícios, silos, armazéns), as diversas formas de energia e combustível e os meios de transporte. O objeto de trabalho é o elemento sobre o qual ocorre o trabalho humano: a terra e as matérias-primas, as jazidas minerais e outros recursos naturais. O termo foi elaborado por Marx, tornando-se de uso corrente em economia." (SANDRONI, 1999, p. 378). 
A educação deve procurar a reconstrução cultural, redarguindo contra ideias disseminadas por aqueles que detêm o capital financeiro e cultural, e que os utilizam como instrumento de controle. Oposição e resistência devem-se pautar por meio da educação, como instrumentos de mudança para a reflexão sobre a eficácia ou ineficácia de conhecimentos sintetizados, e conforme Adorno (1995a, p. 181-182) "despertar a consciência do quanto os homens são enganados de modo permanente".

O caos da civilização humana pode ser combatido por meio de uma educação crítica. Adorno (1995a) alega que a educação, ao ser trabalhada de maneira efetiva, reflexiva, crítica e coerente aos princípios humanos, conduz o homem a possibilidade de impedir a barbárie, o totalitarismo, e a tornar-se senhor de suas próprias determinações. A resistência, a formação crítica e a autonomia, devem ser fomentadas, levando-os ao pensamento humanista. Assim, o homem deve alcançar saberes contemplativos e racionais que proporcionam o desenvolvimento intelectual, cultural, econômico e social. Sem conhecimento, o indivíduo fará parte de um processo centrado na menoridade, relatada por Kant como a "falta de decisão e coragem de servir-se de si mesmo sem a direção de outrem" (KANT, 2008, p. 63).

A intolerância, a incapacidade de se reconhecer em outro e a indiferença alheia são mencionadas por Adorno como barbárie, pois são submetidas a uma lógica desumana. A própria sobrevivência da humanidade se sujeita a superação dessa barbárie:

Portanto, creio que na luta contra a barbárie ou em sua eliminação existe um momento de revolta que poderia ele próprio ser designado como bárbaro, se partíssemos de um conceito formal de humanidade. Mas já que todos nós nos encontramos no contexto de culpabilidade do próprio sistema, ninguém estará inteiramente livre de traços de barbárie, e tudo dependerá de orientar esses traços contra o princípio da barbárie, em vez de permitir seu curso em direção à desgraça (ADORNO; HORKHEIMER, 1985, p. 157). 
As condições de violência encontram dificuldades de serem superadas, visto que a indústria cultural e os detentores do capital manipulam sujeitos por meio de modelos educacionais previamente estabelecidos, tornando-os impotentes e submissos. A autonomia e o estado de maioridade, mencionados por Kant (1995), são suprimidos pela consciência subjugada à ordem estabelecida, que homogeneíza produtos e pessoas.

Por outro lado, a formação do educador, com o intuito de resistir à modelos, tendências e gostos impostos pela indústria cultural, estabelece relações com a educação de resistência contra a repetição dos eventos ocorridos em Auschwitz, descrito por Adorno e Horkheimer (1985). Assim, a educação deve se empenhar em evitar a barbárie contra a consciência humana, possibilitando o desenvolvimento da capacidade de reflexão, da maioridade e da autonomia.

A formação do educador deve compreender a reflexão educacional, focalizada no contexto político-social, conforme Adorno e Horkheimer (1985, p. 15). Partindo-se do pressuposto da formação do indivíduo para o trabalho social, os filósofos relatam que: "A formação que por fim conduziria a autonomia dos homens precisa levar em conta as condições a que se encontram subordinadas a produção e a reprodução da vida humana em sociedade e na relação com a natureza" (ADORNO; HORKHEIMER, 1985, p. 18).

O homem deve ascender à sua condição de maioridade, visando ao discernimento da razão, buscando liberdade, autonomia e emancipação. Conforme Adorno (2011), o homem ao não se opor à ignorância, será como o ouvinte que não tem consciência de sua incompreensão, identificando apenas fragmentos e retalhos da complexidade. Assim, a pseudo-individuação deve ser rechaçada e, por meio de um esclarecimento do processo formativo, busca-se a autonomia do sujeito, que segundo Kant (2008, p. 65) para este esclarecimento, porém, nada mais é exigido, senão a liberdade. 


\section{METODOLOGIA DA INVESTIIGAÇÃO}

Foi desenvolvida uma pesquisa de campo do tipo survey (BABBIE, 1999), por meio da aplicação de questionário online junto a docentes e estudantes de música - em sua maioria docentes de um curso de Licenciatura em Música e licenciandos em música da Instituição de Ensino Superior participante. Foram elaboradas e respondidas quatorze questões. O questionário foi aplicado no mês de junho de 2017. A seleção desse público foi realizada com a intenção de obter percepções de um grupo de sujeitos que tem interesse nos campos da música e formação voltada para atuação docente em música.

\section{Pré-Análise das Respostas ao Questionário}

O questionário, apresentado na tabela 1, a seguir, foi respondido por 82 docentes e estudantes da área de música. As questões intercalaram informações sobre concepções de ensino e perfil de consumo dos participantes.

Tabela 1 - Questionário de opinião aplicado junto a docentes e estudantes de um curso de Licenciatura em Música

\section{Trabalha com ensino de música?}

$\operatorname{Sim}(94,7 \%)$

Não $(5,3 \%)$

2. O seu nível de interesse em educação musical é:

Alto $(92,3 \%)$

Baixo $(5,1 \%)$

Nenhum (2,6\%)

3. Na sua opinião a Educação Musical deve ser focada:

No domínio musical prático e qualidade técnica $(12,2 \%)$

$\mathrm{Na}$ formação de seres humanos mais dóceis e flexíveis $(7,7 \%)$

Na prática musical, incluindo formação humanística $(53,8 \%)$

$\mathrm{Na}$ formação integral, incluindo a técnica $(26,3 \%)$ 
4. Você gostaria de ganhar melhor para poder gastar com: Produtos para luxo e ostentação $(2,5 \%)$

Produtos de melhor qualidade $(52,5 \%)$

Produtos que te valorizem (45\%)

5. Você acredita que a Educação Musical deve abordar a reflexão sobre cidadania, direitos e deveres, valores humanos?

Com certeza, deve abordar $(82,1 \%)$

Não necessariamente $(17,9 \%)$

6. Você costuma comprar por impulso?

$\operatorname{Sim}(25 \%)$

Não $(75 \%)$

7. Em suas aulas de música você discute assuntos relacionados a:

Somente questões musicais $(7,5 \%)$

Prioritariamente questões musicais $(47,5 \%)$

Questões formativas e extras musicais (45\%)

8. Você já comprou produtos em promoção, cujo gasto não estava programado?

$\operatorname{Sim}(67,5 \%)$

Não $(32,5 \%)$

9. Na sua opinião qual a função da educação musical?

Formação instrumental/vocal e conhecimentos musicais (11\%)

Desenvolvimento da criatividade e musicalidade (11\%)

Desenvolver uma consciência cultural e ampliação do repertório musical (6\%)

Sensibilizar e desenvolver a interação humana e social (18\%)

Desenvolver uma consciência crítica e reflexiva da produção musical e da cultura (54\%)

\section{Qual seu sonho como professor de música?}

Ter uma escola de música e desenvolver músicos de alto nível (2,5\%)

Capacitar meus alunos para continuar seus estudos na área musical $(21,5 \%)$

Colaborar para uma formação musical ampla e positiva para o sujeito (27\%)

Atuar de forma positiva na formação de cidadãos conscientes, autônomos, críticos (44\%)

Nenhuma das opções acima (5\%) 


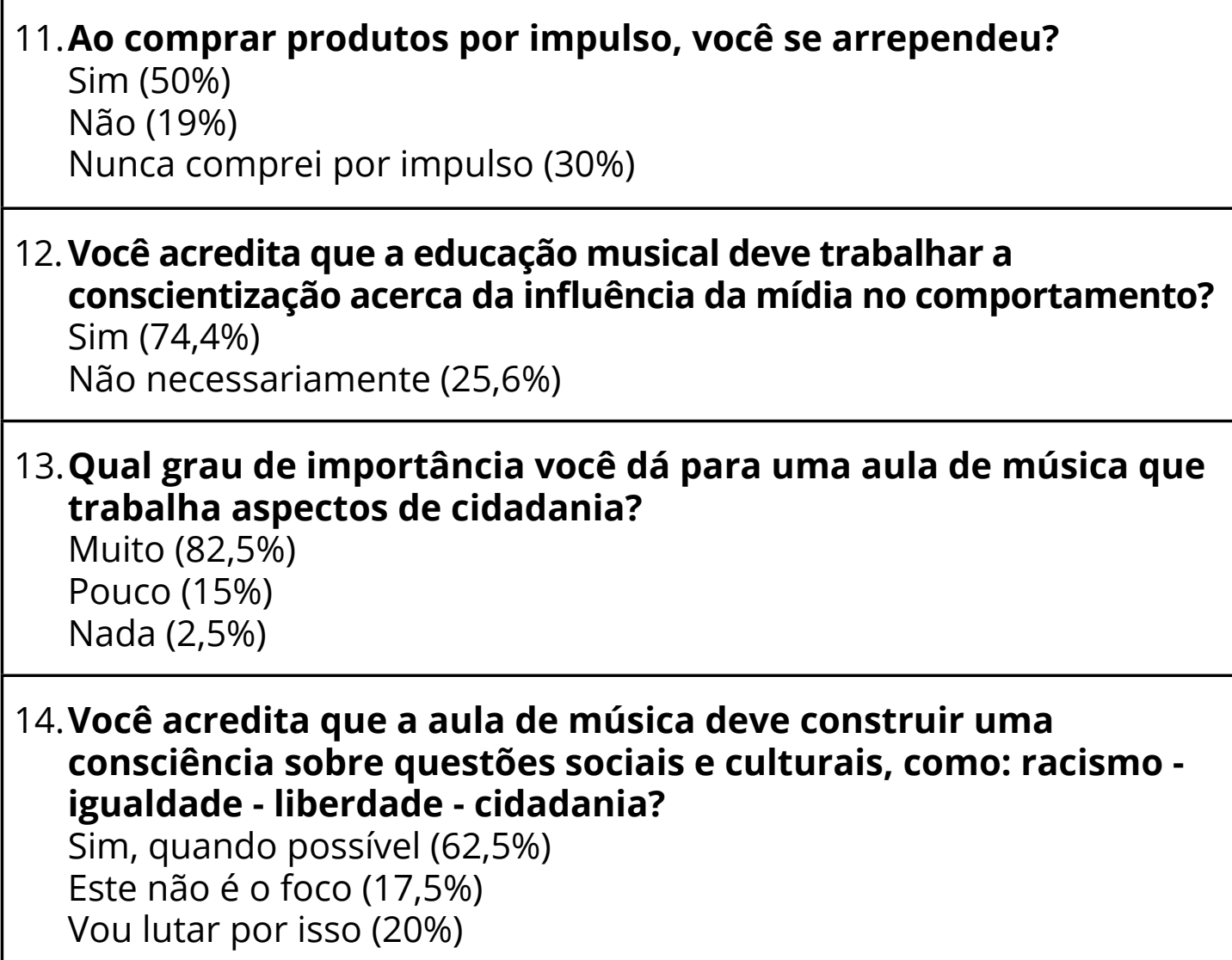

Fonte: Elaborado pelos autores

Constatou-se que, entre os sujeitos que responderam, mais de $94 \%$ já trabalham com ensino de música. Além de buscar a contínua formação em música, o interesse desse público pela área da educação musical é quase unanimidade, sendo que 92,3\% têm alto interesse em educação musical. Nas respostas à terceira questão, verifica-se que há certa opinião de que a formação humana no ensino deve ser concomitante com o ensino técnico musical (53,8\%).

A quarta questão do questionário apresenta dados relativos aos interesses e intenção de consumo. Nesta questão, 45\% dos respondentes, tem interesse em produtos que os valorize, e $52,5 \%$ em produtos de melhor qualidade. Sobre a quinta questão, 82,1\% demonstrou interesse pela educação musical que excede o conhecimento técnico. Na resposta à sexta questão, 
$25 \%$ dos respondentes dizem que já compraram por impulso.

Relativo à concepção de educação musical, e ainda como se desenvolve as aulas de músicas ministradas pelos sujeitos que responderam este questionário, foi incluída a sétima questão, a qual revela que mais da metade dos respondentes abordam conteúdos estritamente musicais em suas aulas.

A oitava questão aborda a porcentagem de indivíduos que adquiriram algum produto que não estava previsto. Dos sujeitos respondentes, apenas 32,5\% dizem que evitaram a compra não programada. Na nona questão os sujeitos ficaram divididos em dois grupos; praticamente a metade, $54 \%$ das respostas, indicam estar em consonância com os ideais de esclarecimento demonstrados por Adorno e Kant. O foco na formação instrumental é para $18 \%$ dos respondentes sobre a função da educação musical. Para outros $11 \%$ o foco é o desenvolvimento da criatividade e musicalidade. O restante, $18 \%$, foca seu trabalho na sensibilização e interação humana.

$\mathrm{Na}$ décima questão, foram dadas várias opções que refletem os objetivos dos respondentes enquanto professores (as) de música. Atuar na formação de cidadãos conscientes, autônomos e críticos foi o item mais escolhido (44\%). A formação musical ampla, focada nos conhecimentos musicais, é o objetivo de $27 \%$ dos respondentes. Comparece em menor grau a concepção de ensino musical propriamente técnico, com o intuito de preparar o aluno para prosseguir os estudos musicais $(21,5 \%)$.

A $11^{\text {a }}$ questão demonstra a insatisfação ou arrependimento ao adquirir um produto por impulso. Nos dados obtidos, percebe-se que a maioria, 51\%, que compraram nessas condições, se arrependeram. Os que não compraram por impulso foram 30\%. As respostas à essa questão corroboram com as respostas à oitava questão e, ambas contradizem as respostas da sexta questão. Ou seja, evidencia-se a compra por impulso, o gasto acima do programado e, ainda, o arrependimento sobre compras realizadas.

A $12^{a}$ questão versa sobre propostas formativas na educação musical. Questiona conteúdos que visam abordar a cons- 
cientização no tocante a indústria cultural e suas pretensões manipuladoras. Assim, verifica-se a necessidade de conscientização dos sujeitos em relação à indústria cultural. No entanto, de acordo com as respostas à $12^{\text {a }}$ questão, $25,6 \%$ dos sujeitos acreditam que isso não deve ser trabalhado na educação musical. No entanto, 74,4\% acham que deve haver espaço para esse processo de conscientização nas aulas.

Foi arguido na $13^{a}$ questão o grau de importância dos aspectos de cidadania nas aulas de músicas. Dos respondentes, $82,5 \%$ consideraram esse item importante. Outros $15 \%$ consideraram pouco importante, e dois sujeitos responderam que isso não é importante.

A última questão, $14^{a}$, trata da temática da formação social, que está inserida principalmente nos aspectos de uma formação cidadã. Contradizendo as questões afins anteriores, as respostas da $14^{a}$ questão indicam que, para os sujeitos, este não deve ser o foco das aulas de música. Para $62,5 \%$ dos sujeitos, as questões sociais e culturais relacionadas à formação integral do indivíduo devem ser abordadas quando possível.

\section{ANALISE COM BASE NAS CATEGORIAS: ‘CONSUMO E INDUÇÃO', ‘MÚSICA E ALIENAÇÃO' E ‘CONSCIẾNCIA E RESIST'ÊNCIA'}

Por meio do questionário proposto aos docentes e estudantes do curso de licenciatura participante, procurou-se investigar a opinião e percepção deles sobre consumo e indução, em relação com temas formativos musicais.

Identifica-se inicialmente a intenção ou não de compra, o desejo e a necessidade como características objetivas. De acordo com as respostas, o produto pode ser adquirido pelo valor que ele agregará à pessoa, o que permite perceber certa relação fetichista, característica da fragilização do sujeito na relação sujeito-objeto (ADORNO, 1995b). Percebe-se que comparecem desejos consumistas, nutridos por certo fascínio motivado pela ideologia dominante, potencialmente obscurecendo a consciência e alimen- 
tando a pseudo-individuação (ADORNO; HORKHEIMER, 1985). Comparecem elementos de como o sujeito relaciona-se com a sociedade sob o domínio da massificação, onde a percepção da pessoa se adapta e se sujeita ao caráter idealista hegemônico.

Nas respostas dos participantes, comparece o discurso da formação humana. Neste sentido, cabem também a relação entre formação musical e formação para cidadania, o que inclui no campo da música a consciência da estrutura e sentido musical (ADORNO, 1994). Nas respostas, percebe-se que a formação técnica, quando focada ou direcionada, tende a dar atenção para a parte e não para o todo. Já a percepção da dimensão total da música e de seus detalhes, produzida a partir da concepção da totalidade, remete o indivíduo a uma ação mais consciente, fundamentando o saber e a compreensão (ADORNO, 1994). Por outro lado, a música na função de consolo, diversão, entretenimento e promotora da alegria, conduz a um comportamento normativo, aludindo à menoridade do indivíduo (ADORNO, 2011; KANT, 2008). Desse modo, parece que para os sujeitos pesquisados a formação humana ainda é apenas um detalhe não relevante ou preponderante no processo educativo musical.

De forma contraditória, as respostas dos sujeitos no questionário demonstram certa preocupação com a formação dos indivíduos, abordando conhecimentos racionais, técnicos e objetivos. Se, por um lado, a música desempenha um papel ideológico representativo, por outro lado, a falsa consciência se sujeita a essa ideologia, limitando a compreensão, o reconhecimento, a percepção e a liberdade.

Podemos afirmar que a alienação é, em todos os aspectos, introjetada, prevalecendo o alheamento da ordem econômica (ADORNO; HORKHEIMER, 1985). Por outro lado, acreditamos que o educador musical, consciente de todo esse processo alienante, poderá viabilizar a autonomia na formação musical, tirando o véu da obscuridade e conduzindo seus alunos e a si mesmo à possibilidade de uma maioridade. Essa autonomia deverá ser uma busca constante do educador, trabalhada por meio de uma formação crítica e ampliadora da consciência (ADORNO, 1995a).

É latente, conforme as respostas ao questionário aplicado, 
que o público pesquisado se preocupa com a formação humana, mas principalmente com a formação técnica musical. Essa formação técnica, por vezes, também pode representar o produto - os resultados. No contexto educativo positivista, o cliente ou aluno estabelece contrato com o professor com objetivos definidos, e esse docente disponibiliza sua mão de obra ou produto.

Questionamos, com base nos fundamentos aqui apresentados, qual deveria ser o objetivo do professor de música; formar músicos ou educar musicalmente? Certamente a técnica estará ao seu dispor, no entanto, o educador só excederá o conteúdo técnico se ele tiver consciência da necessidade de uma formação mais ampla. A formação musical deve ir além do produto, e o professor além da reprodução de técnicas repetitivas e estabelecidas.

Concluímos que a maioria dos sujeitos pesquisados tem interesse por uma educação musical voltada para a formação humana, embora priorizem questões exclusivamente musicais em suas aulas.

\section{CONSIDERAÇÕES FINAIS}

Com base nos estudos aqui desenvolvidos, compreende-se que a resistência aos estímulos, influências e manipulação de comportamentos, desígnio das teorias apontadas, pode e deve compor processos educativos musicais. Os fundamentos teóricos apresentados, quando vinculados a processos de formação podem subsidiar a conscientização do educador e do educando musical, assegurando conteúdos que orientarão a formação humana. Somente a educação, suplantando interesses econômicos, prosperará no sujeito a relutância aos ideários da indústria cultural (ADORNO, 1993a) e do capitalismo tardio (ADORNO, 1993b).

Propor a formação do educador musical orientada para a formação humana - que inclui a emancipação, autonomia e reflexão crítica - conduz à ressignificação de conceitos que norteiam a singularidade do indivíduo, assim como todo o ideário de um campo do saber. 
Nesta pesquisa, tivemos o intuito de refletir sobre os principais pontos discutidos no âmbito teórico-prático e elucidar condições e aspectos percebidos no contexto formativo musical - denunciando contradições no âmbito do ensino musical. Constatamos que os sujeitos participantes possuem consciência da relevância da formação humana da necessidade da inclusão de aspectos críticos e reflexivos nos processos educativos musicais, porém na prática essa inclusão não é prioridade. Deste modo, ampliamos nosso entendimento de como se dão as demandas e as lacunas no campo formativo em música, que carece de fundamentos que revelem com mais afinco a importância da busca e promoção de conhecimentos que proporcionem o desenvolvimento dos indivíduos, frisando a relevância de combate à barbárie.

Baseando-se nessa premissa, inferimos a importância de se buscar, no campo educativo musical, conhecimentos e processos que possibilitam ao sujeito compreender as contradições inerentes às relações sociais. Assim, com base nessa educação voltada para emancipação (ADORNO, 1995a), em detrimento aos processos tecnicistas de dominação, manipulação, consumo e violência, são necessários contínuos empenhos formativos humanizadores. 


\section{REFERÊNCIAS}

ADORNO, T. W. O fetichismo na música e a regressão da audição. In: BENJAMIN, W. et al. Textos escolhidos. $2^{\mathrm{a}}$ ed. São Paulo: Editora Abril Cultural, 1983.

A indústria cultural. In: COHN, G. (org.) Theodor Adorno: sociologia. São Paulo: Ática, $1993 a$.

- Capitalismo tardio ou sociedade industrial? In: COHN, G. (org.) Theodor Adorno: sociologia. São Paulo: Ática, 1993b.

. Sobre música popular. In: COHN, G. (org.) Theodor Adorno: sociologia. 2. ed. São Paulo: Ática, 1994.

. Educação e Emancipação. Rio de Janeiro: Paz e Terra, 1995a.

. Sobre Sujeito e Objeto. In: Palavras e Sinais. Modelos Críticos 2. Trad. de $M^{a}$ Helena Ruschel. Petrópolis - RJ: Vozes, 1995b.

. Introdução à Sociologia da música: doze preleções teóricas. São Paulo: Editora Unesp, 2011.

ADORNO, T. W.; HORKHEIMER, M. Dialética do esclarecimento. Rio de Janeiro: Zahar, 1985.

BABBIE, E. Métodos de Pesquisas de Survey. Belo Horizonte: Editora UFMG, 1999.

BASTOS, R. R. Influência da música ambiente na compra de roupas em lojas. Trabalho de Conclusão de curso. PUC- SP, São Paulo, 2013.

BLACKWELL, R. D.; MINIARD, P. W.; ENGEL, J. F. Comportamento do consumidor. $8^{\mathrm{a}}$ ed. São Paulo: Thompson, 2001. 
COSTA, Cristiano A. Música, Cultura e Formação Humana. In: ZANOLLA, Sílvia R. da S.; TADEU, João R. B. (Org.). Educação, Cultura, diversidade e Formação. $1^{\text {a }}$ ed. Campinas/SP: Mercado de Letras, 2016.

COSTA, Cristiano A. Educação Estética e Música: Possibilidades para o Currículo Integrado. Interlúdio, v. 6, p. 75-86, 2018.

HERRINGTON, J. D.; CAPELLA, L. M. Effects of music in service environments: a field study. The Journal of Services Marketing. v.10, n. 2, p. 26-41, 1996.

HOLBROOK, M. B.; HIRSCHMAN, E. C. The experiential aspects of consumption: consumer fantasies, feelings, and fun. Journal of Consumer Research. v. 9, n. 2, p. 132-140, 1982.

KANT, I. Duas Introduções à Crítica do Juízo. Org. Ricardo Terra, Editora lluminuras Ltda: São Paulo, 1995.

KANT, I. Resposta à pergunta: Que é Esclarecimento? (Aufklärung). In: Textos Seletos. Tradução de Emmanuel Carneiro Leão. 4ª ed. Petrópolis, RJ: Vozes, 2008.

KOTLER, P. Atmospherics as a marketing tool. Journal of Retailing, v. 49, n. 4, p. 48-64, Winter, 1973.

MALHOTRA, N. K. Pesquisa de marketing: uma orientação aplicada. $3^{\text {a }}$ ed. Porto Alegre: Bookman, 2001.

MILLIMANN, R.E. Using Background music to affect the Behavior of Supermarket Shoppers. Journal of Marketing, v. 46, n. 3, p. 86-91, 1982.

MOWEN, J. C.; MINOR, M. S. Comportamento do consumidor. $1^{\text {a }}$ edição. Tradução Vera Jordan. São Paulo: Prentice Hall, 2003. 
PEREIRA, Eliton P. R. Música, formação e indústria cultural: contribuições da teoria crítica da sociedade de Theodor Adorno para o desenvolvimento de pesquisas em formação musical na atualidade. Cadernos de Educação, Tecnologia e Sociedade, v. 9, p. 295-304, 2016.

PEREIRA, Eliton P. R. (org.) Educação, Teoria Crítica e Cultura Musical Contemporânea: pesquisas e propostas de transformação no campo da formação estética. Columbia, EUA: Ed. Amazon, 2017.

RICHARD, Y.; SPANGENBERG, E. Effects of store music on shopping behavior. Journal of Consumer Marketing, v. 7, n. 2, p. 55-63, 1990.

RICHINS, M. L. Measuring emotions in the consumption experience. Journal of Consumer Research, v. 24, n. 2, p. 127-146, 1997.

SANDRONI, Paulo. Novíssimo Dicionário de Economia. Editora Best Seller, 1999.

SHETH, J. N.; MITTAL, B.; NEWMAN, B. I. Comportamento do cliente: indo além do comportamento do consumidor. São Paulo: Atlas, 2008.

UNDERHILL, P. Vamos às compras: a ciência do consumo. Rio de Janeiro: Elsevier, 1999.

ZANOLLA, S. Arte, estética e formação humana: possibilidades e críticas. $1^{\text {a }}$ ed. Campinas - SP: Editora Alínea, 2013. 